\title{
Analysis by Transduction of Mutations affecting Penicillinase Formation in Staphylococcus aureus
}

\author{
By R. P. NOVICK* \\ National Institute for Medical Research, Mill Hill, London, N.W.7
}

(Received 22 April 1963)

\begin{abstract}
SUMMARY
Seventy-five mutants with alterations in penicillinase formation were isolated from a strain of Staphylococcus aureus inducible for penicillinase. The mutants fell into three main categories on the basis of penicillinase activity and inducibility: (i) microinducible mutants which formed decreased amounts of penicillinase but retained the property of inducibility; (ii) penicillinase-negative variants which produced no detectable penicillinase and which showed no effect of inoculum size on penicillin resistance; (iii) strains with a wide range of penicillinase activities that produced the enzyme constitutively. Treatment of the wild-type strain with ethylmethane sulphonate increased the frequency of occurrence of microinducible and constitutive mutants but did not alter the incidence of the penicillinase-negative variants which were present in all cultures at a frequency of about $10^{-3}$. Representative mutants of each class were examined for ability to revert to wild type and to give wild-type recombinants in transductional crosses. The constitutive strains and the microinducible strains behaved like point mutants in that they reverted and in that they gave wild-type recombinants. The penicillinase-negative mutants, however, behaved differently in that they were not observed to revert nor did they give wild-type recombinants in crosses, either with one another or with microinducible or constitutive mutants. A naturally occurring penicillinase-negative strain of $S$. aureus behaved similarly to the penicillinase-negative mutants in these respects. The possibility that the penicillinase region in $\boldsymbol{S}$. aureus is associated with a plasmid and thus inherited extrachromosomally is considered and discussed. The properties of the penicillinase-negative variants could be explained as resulting from the loss of such a plasmid. Consistent with the plasmid hypothesis is the finding that ultraviolet irradiation of transducing phage produced an exponential decline of transducing titre for penicillinase; against it is the failure of acridine orange to increase the frequency of the penicillinasenegative variants.
\end{abstract}

\section{INTRODUCTION}

Naturally occurring penicillin-resistant staphylococci owe their resistance to the production of penicillinase, and the proportion of strains which produce this enzyme has risen steadily since the introduction of penicillin. However, naturally occurring penicillinase-negative staphylococci have never been observed to mutate to penicillinase production (Barber, 1957). Thus, it is currently accepted that the increase in the prevalence of penicillinase-producing strains is primarily the result of selection by penicillin, though phage-mediated transduction of penicillinase-producing capacity

* Present address : The Rockefeller Institute, New York 21, New York. 
may be a contributory factor (Ritz \& Baldwin, 1961). On the other hand, it has been observed that penicillinase-positive strains give rise frequently to penicillinase-negative variants (Barber, 1949; Bondi, Kornblum \& de Saint Phalle, 1953; Fairbrother, Parker \& Eaton, 1954). These strains are usually stable in that, like wildtype penicillinase-negatives, they do not revert to penicillinase production (Fairbrother, 1956). The present work was undertaken with the primary purpose of elucidating the genetic difference between penicillinase-positive and -negative strains of Staphylococcus aureus and the mechanism of 'loss' of penicillinaseforming ability. Since staphylococcal penicillinase is an inducible enzyme (Geronimus \& Cohen, 1957), it was hoped also to study genetically the mechanism of its induction.

The experimental approach to the problem was based on the following argument and was greatly aided by the availability of bacteriophages active in the transduction of the capacity to produce penicillinase to negative strains (Ritz \& Baldwin, 1961; Pattee \& Baldwin, 1961). Apparently the genetic information required for penicillinase synthesis is not present in the penicillinase-negative strains to such a degree of completeness that a single-step mutation can fully restore penicillinaseforming ability. It may be asked, however, whether any of the necessary information is present in these strains and if so, to what extent. A potentially similar situation was studied by Luria, Adams \& Ting (1960), who found that a lac- strain of Shigella which did not mutate to lac + nevertheless had a considerable proportion of the genetic information required for lactose fermentation because lac + recombinants resulted when it was used as a donor in transductional crosses with various Escherichia coli lac - point mutants. Further, this strain of Shigella carried intact the locus controlling the inducibility of the enzymes of lactose fermentation. Similarly, penicillinase-negative strains of Staphyloccus aureus should be able, if they carry any of the requisite genetic information, to repair by recombination a proportion of point-mutational penicillinase losses. On the other hand, if penicillinase-negative strains possess none of the information, no penicillinasepositive recombinants would be expected from crosses with point mutants.

Much of the work to be described has involved the development of media and methods and the isolation and characterization of mutants of Staphylococcus aureus in which penicillinase formation was affected. Transductional crosses have been made with several pairs of the mutants isolated; however, the recombination data thus obtained must be regarded as preliminary. As yet, no penicillinase-positive recombinants have been observed in crosses where one or both parents were naturally occurring penicillinase-negative. The formation of penicillinase-positive recombinants has, however, occurred in crosses between pairs of strains with point mutations in the penicillinase locus.

\section{METHODS}

Media. Preparation and composition of CY media based on CCY medium (Gladstone \& Fildes, 1940) are described in Table 1. The designations, 0.3 CY, $0.5 \mathrm{CY}$ and CY refer to media containing $0.3,0.5$ and $1.0 \%(\mathrm{w} / \mathrm{v})$, respectively, of hydrolysed casein and of yeast extract. The $0 \cdot 3 \mathrm{CY}$ medium gave rather poor growth with the staphylococcal strains used but, with its calcium chloride supplement, permitted excellent growth and plaque formation of the phages. The 0.5 CY medium gave good growth with all of the strains used, and C Ymedium, unsupple- 
mented with calcium, was inhibitory for most of the phages and was used to prevent the destruction of transductants in crosses mediated by non-lysogenizing phage. It was also used when especially dense cultures were desired, e.g. in penicillinase induction experiments.

Andrade indicator agar (Kogut, Pollock \& Tridgell, 1956) was supplemented with yeast extract, $0.5 \%(\mathrm{w} / \mathrm{v})$, starch, $0.3 \%(\mathrm{w} / \mathrm{v})$, and, usually, benzylpenicillin, $0 \cdot 10 \mu \mathrm{g} . / \mathrm{ml}$.

\section{Table 1. Preparation and composition of $C Y$ media and buffer}

Media were prepared with de-ionized water and autoclaved at $115^{\circ}$ for $25 \mathrm{~min}$. in screwcapped bottles for storage.

\begin{tabular}{|c|c|c|c|c|}
\hline & $\begin{array}{l}\text { Phage buffer; } \\
\text { for } \\
\text { harvesting, } \\
\text { dilutions, } \\
\text { and storing } \\
\text { of phage }\end{array}$ & $\begin{array}{c}0 \cdot 3 \mathrm{CY} \text {; for } \\
\text { propagation, } \\
\text { titration, } \\
\text { and spot } \\
\text { testing of } \\
\text { phage }\end{array}$ & $\begin{array}{l}0.5 \mathrm{CY} \text {; for } \\
\text { routine } \\
\text { culture } \\
\text { medium }\end{array}$ & $\begin{array}{c}\text { CY; for } \\
\text { selection of } \\
\text { transductants } \\
\text { by using non- } \\
\text { lysogenizing } \\
\text { phages and } \\
\text { for } \\
\text { penicillinase } \\
\text { induction }\end{array}$ \\
\hline$\beta$-Glycerophosphate* & $0.06 \mathrm{M}$ & $0.06 \mathrm{M}$ & $0 \cdot 06 \mathrm{M}$ & $0.12 \mathrm{M}$ \\
\hline $\mathrm{MgSO}_{4}$ & $0.001 \mathrm{M}$ & $0.001 \mathrm{M}$ & $0.001 \mathrm{M}$ & $0.001 \mathrm{M}$ \\
\hline $\mathrm{CaCl}_{2} \dagger$ & $0.004 \mathrm{M}$ & $0.004 \mathrm{M}$ & - & - \\
\hline $\mathrm{NaCl}$ & $0.085 \mathrm{M}$ & - & - & - \\
\hline Glucose $\dagger$ & - & 一 & $0.028 \mathrm{M}$ & $0.028 \mathrm{M}$ \\
\hline Gelatin & $0.1 \%(w / v)$ & - & 一 & - \\
\hline Trace metals & - & $0.02 \mathrm{ml} . / 1$. & $0.02 \mathrm{ml} . / 1$ & $0.02 \mathrm{ml} . / \mathrm{l}$ \\
\hline Yeast extract (Difco) & 一 & $0.3 \%(w / v)$ & $0.5 \%(w / v)$ & $1.0 \%(w / v)$ \\
\hline $\begin{array}{l}\text { Acid hydrolysed casein } \\
\text { (Difco) }\end{array}$ & - & $0.3 \%(w / v)$ & $0.5 \%(w / v)$ & $1.0 \%(w / v)$ \\
\hline $\begin{array}{l}\text { Agar (Difco), when } \\
\text { required }\end{array}$ & - & $1.5 \%(w / v)$ & $1.5 \%(w / v)$ & $1.5 \%(\mathrm{w} / \mathrm{v})$ \\
\hline
\end{tabular}

* Added after autoclaving when agar was present. $\dagger$ Added after autoclaving. $\ddagger 0.5 \%(w / v)$ $\mathrm{CuSO}_{4} ; 0.5 \%(\mathrm{w} / \mathrm{v}) \mathrm{ZnSO}_{4} ; 0.5 \%$ (w/v) $\mathrm{FeSO}_{4} ; 0.2 \%$ (w/v) $\mathrm{MnCl}_{2} ; 10 \%$ (v/v) $\mathrm{HCl}$.

Phage buffer. The composition of phage buffer is shown in Table 1. It was used for harvesting, storing, and diluting phage lysates.

Acid-base indicator agar. Agar, $1.5 \%(\mathrm{w} / \mathrm{v})$, with benzylpenicillin, $10 \mathrm{~mm}$ and an acid-base indicator, N-phenyl-1-naphthylamine-azo-0-carboxybenzene (mM) was poured in $200 \mathrm{ml}$. quantities on plate glass squares, using a $32 \times 32 \mathrm{~cm}$. Perspex frame. This particular indicator was chosen because its acid form is insoluble in water; acid production was thus indicated by sharply localized non-diffusing haloes.

Starch iodide indicator agar. Agar, $1.5 \%$ (w/v), with benzylpenicillin $0.5 \mathrm{~mm}$, iodine $1.0 \mathrm{~mm}$, and starch (Analar) $0.3 \%(\mathrm{w} / \mathrm{v})$, was poured in $120 \mathrm{ml}$. quantities on the plate glass squares.

\section{Organisms}

Bacterial strains. Staphylococcus aureus was used exclusively in this work. Strain 524 SC (Rogers, 1953) is a laboratory strain; strain U-9 was kindly provided by Dr P. A. Pattee; strains NCTC 8510,8511 , and 8325 are the propagating strains for phages 7, 53, and 47, respectively, of the International Typing Series. The series of propagating strains was obtained from the Central Public Health Laboratories, Colindale, London, N.W. 9. All strains were stored on blood agar slopes and were 
renewed from dried preparations (Stamp, 1947) at 6-month intervals. See Table 2 for relevant phenotypic characteristics.

Parental substrains. See Table 2. A heterogenetic penicillinase-inducible substrain of 8325 , designated $8325-18$, was constructed by transduction with phage $53 \alpha$ using strain 524 $\mathrm{sc}$ as the donor. This was done to make possible the isolation of a group of secondary penicillinase-negatives derived from the original wild type, 8325. A streptomycin-resistant mutant $(0.5 \mathrm{mg} . / \mathrm{ml}$.) designated s-1 was selected after ethylmethane sulphonate (EMS) treatment of 8325-18. From these two strains were isolated all of the mutants used in this work. Strain $\mathrm{y}-4$ is a yellow

Table 2. Characteristics of wild-type strains and of parental substrains of Staphylococcus aureus

\begin{tabular}{|c|c|c|c|}
\hline Strain & Phage type & Penicillinase & $\begin{array}{l}\text { Reaction to } \\
\text { streptomycin } \\
(0.5 \mathrm{mg} . / \mathrm{ml} .)\end{array}$ \\
\hline 524 sc & 一 & Inducible & $\mathbf{S}^{*}$ \\
\hline U-9 & $80 / 81 \dagger$ & Inducible & $\mathbf{R}$ \\
\hline 8510 & $6 / 7 / 47 / 53 / 54 / 75 / 77 \ddagger$ & Negative & 一 \\
\hline 8511 & $53 / 54 / 75 / 77 t$ & Inducible & - \\
\hline 8325 & $47 / 75$ & Negative & $\mathbf{S}$ \\
\hline 8325-18 & $29 / 47 / 75$ & Inducible & $\mathbf{S}$ \\
\hline $\mathrm{s}-1$ & $29 / 47 / 53 / 75 / 77$ & Inducible & $\mathbf{R}$ \\
\hline $\mathbf{y}-\mathbf{4}$ & - & Inducible & $\mathbf{R}$ \\
\hline
\end{tabular}

pigmented mutant of s-1 which occurred spontaneously. It should be emphasized that a heterogenetic strain cannot be assumed to be genetically equivalent to a wild type; the interpretation of the results to be reported is therefore of limited generality pending the examination of possible differences between the two.

Growth experiments. Opacity, dry weight and viable count were determined for a suspension of 8325 harvested during exponential growth, centrifuged and resuspended in $0.15 \mathrm{M}$-sodium chloride. An opacity of 0.10 on the Hilger 'Spekker' absorptiometer, with an Ilford filter No. 508, corresponded to $0.022 \mathrm{mg}$. bacterial dry wt. $/ \mathrm{ml}$. This bacterial concentration usually gave about $4 \times 10^{7}$ colony-forming units $/ \mathrm{ml}$., corresponding to about $10^{8}$ organisms $/ \mathrm{ml}$., since the staphylococci usually grew in clumps of 2-4.

For penicillinase induction tests, strains were grown overnight on $0.5 \mathrm{CY}$ slopes and inoculated into prewarmed CY medium containing $\mu \mathrm{M}$ 2,6-dimethoxyphenylpenicillin (methicillin) to give a suspension equivalent to $0.02-0.04 \mathrm{mg}$. dry wt. bacteria $/ \mathrm{ml}$. The cultures were then shaken at $35^{\circ}$ and at the end of $5 \mathrm{hr}$. were chilled in ice and their opacities measured. Uninduced cultures for penicillinase measurement were identical except that methicillin was omitted.

Bacteriophage strains. The phages of the International Typing Series were obtained from the Central Public Health Laboratories, Colindale, London, N.W. 9. A few single plaques were obtained when phages 53 and 80 were plated on strains 524 sC and 8325 , respectively, using $10^{8}$ plaque-forming units/plate. The phage strains thus isolated were designated as $53 \alpha$ and $80 \alpha$; it is not known whether they are 
host-range mutants or host-induced phenotypic modifications. Phage $47^{\prime}$ is a temperate phage carried by strain 8325 in the prophage state.

Propagation of phages was done in $\mathbf{0 . 3} \mathrm{CY}$ broth or by the soft agar layer method of Swanstrom \& Adams (1951) with 0.3 CY medium plates. Temperate phage lysates were obtained by ultraviolet (u.v.) irradiation, with a u.v. dose of radiation which gave 90-95\% survival of a non-lysogenic derivative of the same strain. Bacteria were irradiated in $\mathbf{0 . 1 5} \mathrm{M}$-sodium chloride and were then incubated in $\mathbf{0 . 3} \mathrm{CY}$ broth with gentle shaking at $35^{\circ}$ until lysis was complete (usually about $3 \mathrm{hr}$.). Phage lysates were clarified by centrifugation and bacteria removed by membrane filtration. Phage concentrates free from growth medium for use in u.v.-irradiation experiments were prepared by centrifugation for $75 \mathrm{~min}$. at $35,000 \mathrm{~g}$ in the Spinco model L preparative centrifuge. The bacterial strains used as indicators for the titration of the phages were 8511 for phage 53, U-9 for phage 80, 8325 for phages $53 \alpha$ and $80 \alpha$, and 8510 for phage $47^{\prime}$.

Transduction experiments. Recipient organisms were grown overnight on $0.5 \mathrm{CY}$ slopes and were inoculated into $0.5 \mathrm{CY}$ medium to give equiv. $0 \cdot 2-0 \cdot 4 \mathrm{mg}$. dry wt. bacteria $/ \mathrm{ml}$. These cultures were shaken at $35^{\circ}$ until they had grown to a density of about equiv. $1.0 \mathrm{mg}$. dry wt./ml. and were then mixed with an equal volume of phage in phage buffer. Calcium chloride was added to a final concentration of $4 \mathrm{~mm}$. For non-lysogenizing phage, multiplicities of infection were $0 \cdot 3-1 \cdot 0$; for temperate phage, $1 \cdot 0-10$. After further incubation for $45 \mathrm{~min}$. with gentle rocking at $35^{\circ}$, the cocci were washed by centrifugation or membrane filtration to remove free penicillinase and were then plated on appropriate media in soft agar $(0.5 \%$, $\mathrm{w} / \mathrm{v}$ ) overlays. In some experiments they were plated directly on selective medium containing benzylpenicillin (0.06-0.12 $\mu \mathrm{g} . / \mathrm{ml}$.). In other experiments they were plated in soft agar layers on the surface of cellophan or cellulose acetate membranes (Oxoid) and incubated for $2 \mathrm{hr}$. at $35^{\circ}$ on non-selective medium before being transferred to plates containing penicillin. After a further incubation for 18-24 hr. at $35^{\circ}$, penicillinase-positive colonies were usually distinguishable by their haloes of penicillin-sensitive satellites. The transductants were always confirmed on the plates by one of the definitive penicillinase-detection methods and in some cases were scored for unselected markers and tested for penicillinase inducibility.

\section{Detection and measurement of penicillinase}

Measurement. Penicillinase activities are expressed in units as defined by Pollock $\&$ Torriani $\left(1953\right.$; one unit $=1 \mu$ mole penicillin hydrolysed $/ \mathrm{ml} . / \mathrm{hr}$. at $30^{\circ}$ ), with the exception that $\mathrm{pH} 5.8$ was used instead of $\mathrm{pH} 7 \cdot 0$ since staphylococcal penicillinase is optimally active at pH $5 \cdot 8$ (Novick, $1962 a$ ).

For activities greater than 0.5 units $/ \mathrm{ml}$., penicillinase was assayed by the method of Perret (1954). This method could be used with whole cultures, washed cocci, or culture fluids. For measurement of lower penicillinase activities, the following modification, by Dr D. Dubnau (unpublished), of the micro-iodometric method of Novick $(1962 b)$ was used. The cocci to be assayed were centrifuged and resuspended in $0.15 \mathrm{M}$ sodium chloride to give a maximum suspension concentration equiv. $10 \mathrm{mg}$. dry wt. bacteria/ml. A dilution was made for opacity determination, and a $1 \mathrm{ml}$. sample containing from $0 \cdot 010$ to $0 \cdot 10$ units of penicillinase activity was pipetted into a plastic centrifuge tube at $30^{\circ}$ containing $1 \mathrm{ml} .0 \cdot 2$ mm-sodium 
benzylpenicillin in 0.1 M-sodium phosphate buffer $(\mathrm{pH} 5 \cdot 8)$ with $0 \cdot 15 \%(\mathrm{w} / \mathrm{v})$ gelatin. After incubation for $1 \mathrm{hr}$. at $30^{\circ}, 1 \mathrm{ml}$. of $0.15 \mathrm{M}$-sodium tungstate in $2 \cdot 0 \mathrm{M}$-sodium acetate buffer ( $\mathrm{pH} 4.0$ ) was added to stop the reaction (Csányi, 1961). Each sample had a control in which substrate alone was incubated, enzyme being added after adding the tungstate. Tubes were then centrifuged at $3000 \mathrm{rev} . / \mathrm{min}$. for $10 \mathrm{~min}$., decanted, and $2 \mathrm{ml}$. of supernatant fluid added to $2 \mathrm{ml}$. of starch iodide reagent. The starch iodide reagent (Novick, 1962b) contained $0.4 \%(\mathrm{w} / \mathrm{v})$ starch with $80 \mu \mathrm{m}$-iodine and $\mathbf{1 . 6} \mathrm{mm}$-potassium iodide. After $10 \mathrm{~min}$. at room temperature (about $18^{\circ}$ ) each sample was read against its own control in $0.5 \mathrm{~cm}$. cuvettes in a Spekker absorptiometer, with an Ilford filter No. 607. The assay gave extinctions that were a linear function of enzyme activity. Readings were converted to enzyme activities with the aid of a standard curve obtained with an enzyme preparation of known activity. The lower limit of sensitivity of the assay was 0.001 units penicillinase/mg. dry wt. bacteria. The advantage of this modification lay in stopping the reaction; thus many samples could be run simultaneously.

Detection. Penicillinase activity was detected in colonies growing on plates by two techniques. The starch iodide test of Perret (1954) gave a positive result with strains that had as little activity as 0.05 units penicillinase/mg. dry wt. bacteria. This method was used to screen suspected penicillinase-negative mutants and to identify penicillinase-positive recombinants on membranes. The Andrade indicator method (Kogut et al. 1956) gave a positive reaction only with colonies that had at least 50 units penicillinase activity/mg. dry wt. bacteria. Constitutive mutants and induced wild-type strains gave a positive Andrade test, while uninduced wild-type strains were negative. Thus the method was useful for testing suspected constitutive mutants and for testing penicillinase-positive transductants for inducibility.

\section{Mutations involving penicillinase formation}

Induction with ethylmethane sulphonate (EMS). All of the mutations studied in this investigation were induced by EMS according to the procedure of Loveless \& Howarth (1959). Strains to be treated were prepared as for transduction experiments. Two ml. of whole culture were added to $0.08 \mathrm{ml}$. of EMS which was dissolved by gentle pipetting. The bacterial suspension was incubated at $35^{\circ}$ for $20 \mathrm{~min}$., $8 \mathrm{ml}$. of $0 \cdot 15 \mathrm{M}$-sodium chloride added, the bacteria centrifuged down, then resuspended in $10 \mathrm{ml} .0 .5 \mathrm{CY}$ broth and incubated for $4 \mathrm{hr}$. at $35^{\circ}$, with shaking before plating.

Isolation of mutants. A method was developed for the isolation of penicillinasenegative and penicillinase-constitutive organisms. This was based on a procedure in which a population of colonies was first grown on a membrane and then transferred to a penicillinase-indicating medium (Knox \& Smith, 1961). In the present method, the reason for the transfer step is that the indicator was growth-inhibitory and thus could not be incorporated into the growth medium. To screen large numbers of organisms, $30 \times \mathbf{3 0} \mathrm{cm}$. glass trays (Jencons, Ltd., Hemel Hempstead, Hertfordshire, England) were used for growing the colonies. To avoid acid formation during growth, glucose was omitted. A cellophan membrane on each agar surface was spray-inoculated with $10^{4}-10^{5}$ colony-forming units suspended in $5 \mathrm{ml}$. soft $(0.5 \%, \mathrm{w} / \mathrm{v})$ agar. This was followed by a further $5 \mathrm{ml}$. of soft agar to prevent spreading of the colonies. The trays were incubated overnight and were dried for 
$2 \mathrm{hr}$. at $35^{\circ}$ with lids off. The membranes were then transferred to acid-base indicator agar and after further incubation (usually 2-4 hr.), three different phenotypes were readily distinguishable: (i) wild-type inducibles had small intense purple haloes, (ii) constitutives had large ones, (iii) penicillinase-negative colonies were white on a reddish background. To recover negatives it was necessary to subculture on agar containing penicillinase ( 2 units/plate). Thus far 55 penicillinase-negative and 20 penicillinase-constitutive mutants have been isolated.

Table 3. Classification of mutants of Staphylococcus aureus

\begin{tabular}{|c|c|c|c|}
\hline Penicillinase phenotype & $\mathbf{u}^{*}$ & $\begin{array}{c}\text { Induction } \\
\text { ratio } \\
(\mathrm{i} / \mathrm{u})\end{array}$ & $\begin{array}{c}\text { Class } \\
\text { designation }\end{array}$ \\
\hline Wild-type, inducible & $\sim 10$ & $\sim \mathbf{3 0}$ & pen-rw \\
\hline Wild-type, penicillinase-negative & $<0.001$ & - & pen-sw \\
\hline $\begin{array}{l}\text { Loss mutants sensitive } \ddagger \text { to } \\
\text { penicillin }\end{array}$ & $<0.001$ & - & pen-sd \\
\hline Constitutive & $>10$ & $<\mathbf{5}$ & $p e n-c$ \\
\hline Microconstitutive & $<10$ & $<5$ & pen-mc \\
\hline Mesoinducible & $0 \cdot 1-10$ & $>5$ & pen-mei \\
\hline Microinducible & $<0.1$ & $>5$ & pen-mi \\
\hline
\end{tabular}

* Enzyme concentration in units/mg. dry wt. bacteria in whole cultures in absence of inducer.

$\uparrow$ Ratio of enzyme concentration of fully induced culture to concentration in culture grown in absence of inducer.

¥ Sensitive is used to signify that there was no demonstrable effect of inoculum size on minimal inhibitory concentration of penicillin.

Nomenclature and classification of mutants. Penicillinase activities were measured for most of the mutants, both those induced with methicillin and those uninduced. Unexpectedly, many of the supposed penicillinase-negative strains turned out to have appreciable amounts of penicillinase ranging from barely detectable amounts to just lower than the wild-type values, and with induction ratios varying from 1 to 50. It was found convenient to classify the mutants phenotypically. The nomenclature is based on that adopted by Pollock (1957), the various classes having been delimited arbitrarily as shown in Table 3. Thus, all mutants with induction ratios smaller than 5 were classified as constitutive; in this group, those with uninduced penicillinase activities lower than that of uninduced wild type were termed microconstitutive. Among the mutants with induction ratios larger than 5, the inducible class, those with uninduced penicillinase values below $0 \cdot 1$ unit penicillinase/mg., have been termed microinducible, while those which were between that value and the uninduced wild-type value were designated mesoinducible. A final class, mutants with no detectable penicillinase activity, have been termed pen-sd mutants.

\section{RESULTS}

Penicillinase levels of mutants. In Table 4 are listed the penicillinase values obtained for a representative sample of the mutants. The penicillinase activities for strains with uninduced values below 0.1 unit/mg. dry wt. organism were measured by the micro-assay with washed cocci. All the others were measured by the iodometric assay (Perret, 1954) with whole cultures. Since staphylococcal penicillinase is generally 40-60\% extracellular (Novick, 1962a) in mutants as well as in wild- 

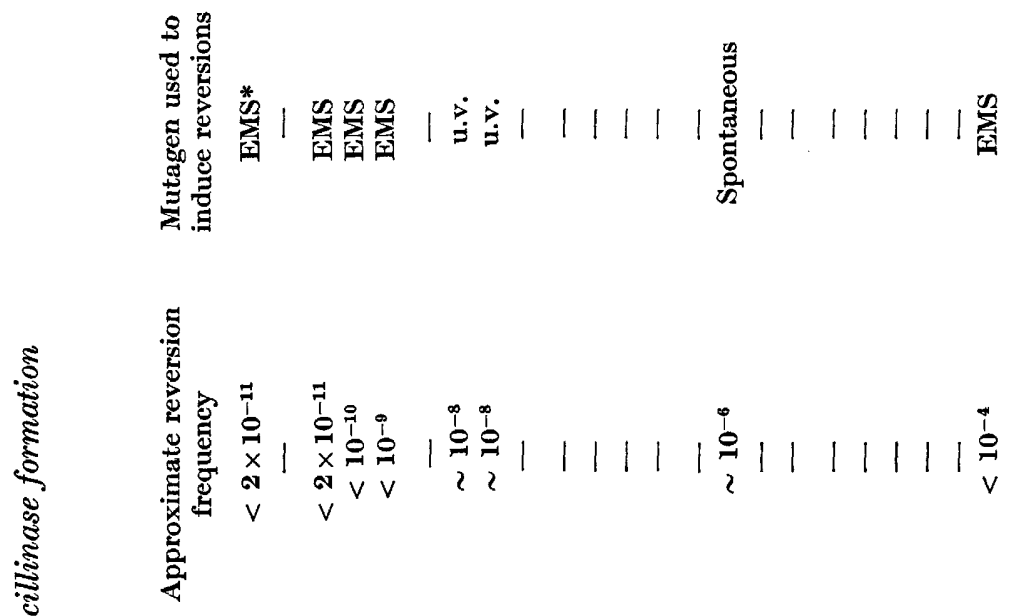

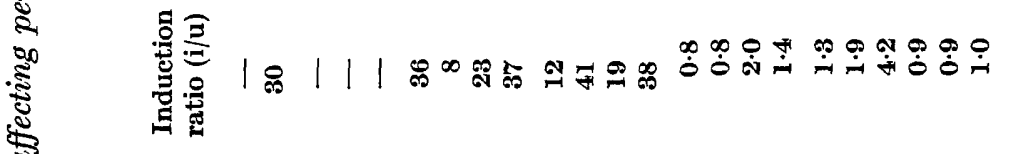
?. 总

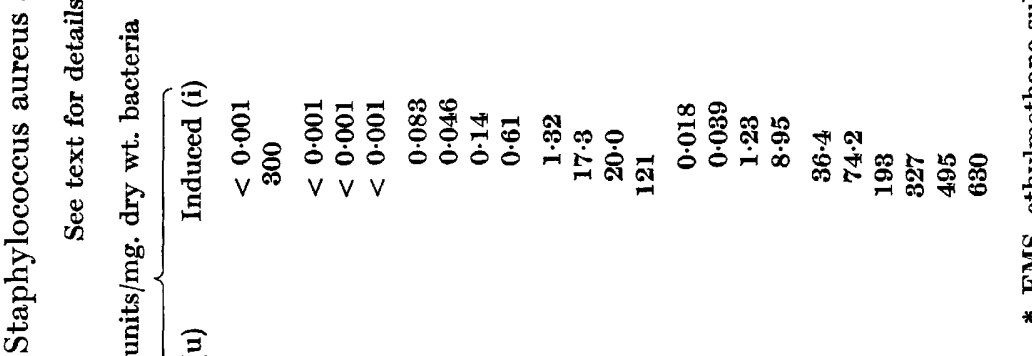

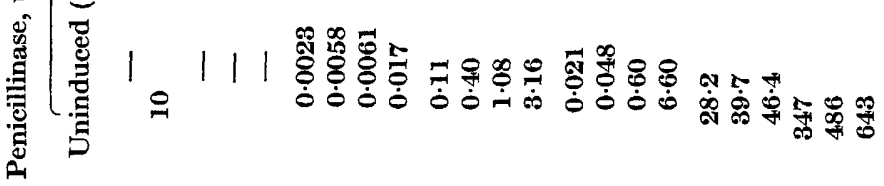

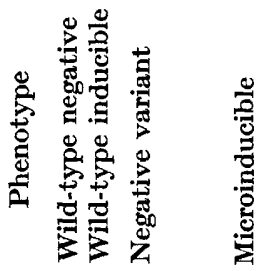

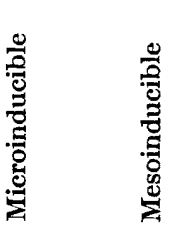

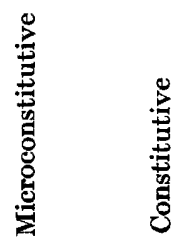

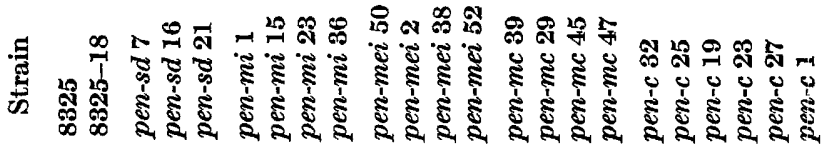


type strains, measurements carried out with washed cocci are too low by a factor of about 2. Table 4 shows that in both the inducible and constitutive groups there was a continuous range of penicillinase values.

Mutation frequencies. In Table 5 are noted the approximate frequencies of occurrence of the three major classes of mutants, both spontaneous and after EMS treatment. Mutation to streptomycin resistance $(0.5 \mathrm{mg} . / \mathrm{ml}$.) is included for comparison. Table 5 shows (1) that EMS, while increasing the yield of all mutants with residual penicillinase activity by $10^{2}-10^{3}$-fold, appeared to have no effect on the incidence of pen-sd strains; (2) that the frequency of pen-sd was about $10^{-3}$ (this has been found for other strains also, as will be seen in a later section); (3) that the frequency of EMS-induced mutations involving penicillinase in this strain is higher than it is for streptomycin resistance and for various markers in other organisms (Loveless \& Howarth, 1959; Strauss, 1962).

\section{Table 5. Approximate frequencies of occurrence of various mutant types of Staphylococcus aureus}

$S$. aureus strain 8325-18 was plated on cellophan membranes on 0.5 CY agar without glucose to give $10^{5}-10^{8}$ colonies on each membrane. The cocci were either plated directly or were treated with ethylmethane sulphonate(EMS) and then incubated for $4 \mathrm{hr}$. in $0.5 \mathrm{CY}$ broth before plating. After overnight incubation, the membranes were transferred to acid-base indicator agar and the various types were picked and scored. For streptomycin resistance, $10^{9}$ cocci were plated on $0.5 \mathrm{CY}$ agar with streptomycin $(0.5 \mathrm{mg}$. $/ \mathrm{ml}$.) both untreated and following EMS treatment and incubation.

Penicillinase phenotype

Constitutive

Sensitive

Microinducible + mesoinducible + microconstitutive

Streptomycin resistant

\begin{tabular}{|c|c|}
\hline \multicolumn{2}{|c|}{ Frequency } \\
\hline Spontaneous & EMS-treated \\
\hline $10^{-6}$ & $5 \times 10^{-4}$ \\
\hline $10^{-3}$ & $10^{-3}$ \\
\hline $10^{-5}$ & $5 \times 10^{-4}$ \\
\hline $5 \times 10^{-9}$ & $3 \times 10^{-6}$ \\
\hline
\end{tabular}

Reversions. Several of the mutants were tested for reversion to wild type with regard to penicillinase production. In some cases, cultures were treated with EMS and allowed 6-18 hr. of growth in non-selective medium before plating. Alternatively, cultures were u.v.-irradiated to $1 \%$ survival, allowed to grow overnight in non-selective medium, and then plated on penicillin for selection of revertants; the results are shown in Table 4. No revertants were obtained either spontaneously, with u.v.-radiation, or with EMS treatment from any of the pen-sd strains or from strain 8325. Of three strains tested that had detectable penicillinase activity, all gave revertants. The results with one strain, pen-mc 29, were interesting in that of 130 revertants, 100 gave positive Andrade reactions, indicating that they were highlevel constitutives. The other $\mathbf{3 0}$ gave negative Andrade tests, both with and without the inclusion of methicillin in the agar; these might have been microconstitutives or microinducibles, but not wild-type inducibles. Strains pen-mi 15 and pen-mi 23, on the other hand, both gave rise to revertants which were mostly wild-type inducible by the Andrade test. None of the revertants has yet been tested further.

\section{Genetic analysis}

Phenotypic lag. A transduction experiment was carried out in which phage $4 \boldsymbol{7}^{\prime}$ prepared from strain 8325-18 was used to infect strain 8325. After absorption of 
phage, the recipient cocci were plated on Oxoid membranes on $0.5 \mathrm{CY}$ medium, incubated for $2 \mathrm{hr}$., then transferred to $0.5 \mathrm{CY}$ medium with $0.08 \mu \mathrm{g}$. penicillin $/ \mathrm{ml}$. This $2 \mathrm{hr}$. incubation period resulted in a fourfold increase in total transductants over a control plated directly on penicillin-containing agar. It has not been established whether this effect was the result of delayed expression of the newly received penicillinase gene or was due simply to the growth of penicillinase-positive transductants into more resistant microclones during the 2-hr. period before challenge. When the technique of incubation on non-selective medium before challenge with penicillin was used, transduction frequencies of about $5 \times 10^{-5} /$ plaque-forming unit were obtained with phage $\mathbf{4} \mathbf{7}^{\prime}$.

Recombination between pen-sd and microinducible strains. To explore further the genetic basis of the pen-sd mutants and the wild-type penicillinase-negatives (pen-sw), and also to begin mapping the penicillinase region, various recombination experiments were carried out as listed in Table 6. Phage $47^{\prime}$ at a multiplicity of 10 was used for most of the crosses; phage $80 \alpha$ at a multiplicity of 1.0 was used for a few. In most experiments, the selective penicillin concentration was $0.09 \mu \mathrm{g} . / \mathrm{ml}$; the cocci were usually pre-incubated on membranes for $2 \mathrm{hr}$. before transfer to penicillin. Recombinants were identified on starch iodide indicator agar and were confirmed by scoring unselected markers.

Table 6. Recombinations between pen-sd, pen-sw, microinducible and microconstitutive strains of Staphylococcus aureus

See text for details.

\begin{tabular}{|c|c|c|c|c|c|}
\hline \multirow[b]{2}{*}{ Donor } & \multirow[b]{2}{*}{ Recipient } & \multirow[b]{2}{*}{$\begin{array}{l}\text { Phage } \\
\text { input }\end{array}$} & \multirow[b]{2}{*}{ m.o.i.* } & \multicolumn{2}{|c|}{ Recombinants } \\
\hline & & & & Inducible & $\begin{array}{c}\text { Con- } \\
\text { stitutive }\end{array}$ \\
\hline pen-mi 1 & pen-mi 15 & $10^{9}$ & 10 & 150 & 0 \\
\hline pen-mc 29 & pen-mi 15 & $10^{9}$ & 10 & 100 & 0 \\
\hline pen-mc 29 & pen-mi 1 & $10^{9}$ & 10 & $\mathbf{3 0}$ & $\mathbf{0}$ \\
\hline pen-mc 29 & pen-sw† & $10^{10}$ & 10 & 0 & $\mathbf{0}$ \\
\hline pen-mc 29 & pen-sd 16 & $10^{10}$ & 10 & $\mathbf{0}$ & 0 \\
\hline pen-mi 1 & pen-sd 16 & $10^{10}$ & 10 & 0 & $\mathbf{0}$ \\
\hline pen-mi 15 & pen-sd 7 & $10^{9}$ & 1 & 0 & $\mathbf{0}$ \\
\hline$p e n-s d 7$ & each of 7 pen-sd strains & $10^{9}$ & 1 & $\mathbf{0}$ & $\mathbf{0}$ \\
\hline
\end{tabular}

The results given in Table 6 show that when any pen-sd or pen-sw strain was used either as donor or as recipient in a cross, no wild-type recombinant was observed. When two microinducible strains were crossed, wild-type recombinants were obtained in all of the combinations tried. This was also true for crosses in which the microconstitutive, pen-mc 29, was used as donor. No polarity was observed in reciprocal crosses.

Linkage of structural and control loci. Although pen-sd and pen-sw strains did not give recombinants among one another or with microinducible strains, it was nevertheless possible that they might have the locus responsible for the inducibility of the enzyme. To test for this, several crosses were done, the results of which are given in Table 7. These crosses were scored for transductants having the donor phenotype and for novel phenotypes which might have arisen by recombination within the 
penicillinase region. In one cross, with a constitutive strain pen-c 1 as donor and a microinducible strain pen-mi 15 as recipient, wild-type inducible recombinants occurred at a frequency of about $0 \cdot 6 \%$ of the total transductants. Thus, the sites of these two mutations are tightly but not inseparably linked. In two other crosses with the same donor, but with pen-sd or pen-sw strains as recipients, no such recombinants were observed; all the transductants had the constitutive phenotype of the donor.

\section{Table 7. Linkage of structural and control loci for penicillinase in Staphylococcus aureus}

\begin{tabular}{|c|c|c|c|c|c|}
\hline \multirow{3}{*}{\multicolumn{6}{|c|}{$\begin{array}{l}\text { Transducing phage was mixed with recipient staphylococci and incubated for } 45 \mathrm{~min} \text {. } \\
\text { The coccal suspensions were then membrane filtered or centrifuged to remove penicillinase } \\
\text { and unadsorbed phage and were plated on cellophan membranes on } 0.5 \mathrm{CY} \text { agar without } \\
\text { glucose, with } 0 \cdot 12 \mu \mathrm{g} \text {. benzylpenicillin/ml. Transductants were scored on indicator } \\
\text { agar after overnight growth and several colonies of each class were tested on Andrade } \\
\text { plates for confirmation of phenotype. } \\
\text { Phage }\end{array}$}} \\
\hline & & & & & \\
\hline & & & & & \\
\hline 8325-18 & pen-swe & $10^{9}$ & 1 & 25,000 & 0 \\
\hline pen-c 1 & pen-sw† & $10^{9}$ & 1 & 0 & 8000 \\
\hline pen-c 1 & pen-sd 7 & $10^{9}$ & 1 & 0 & 3000 \\
\hline pen-c 1 & pen-mi 15 & $10^{8}$ & 10 & 3 & 500 \\
\hline
\end{tabular}

Clearly, the pen-sd mutants are not allelic to pen-c 1 , so that in failing to give wildtype recombinants in crosses with the latter, they behaved as though they lack the regulatory locus which carries the mutation of pen-c 1 . The possibility that the pen-sd strains tested are double mutants carrying a lesion allelic to pen-c 1 as well as another, is made unlikely by the failure to obtain constitutive recombinants in crosses with the wild-type inducible strain 8325-18.

Effect of ultraviolet-irradiation. Figure 1 shows the results of an experiment in which a suspension of phage $80 \alpha$ was u.v.-irradiated and serial determinations of transducing and plaque-forming titres carried out. As can be seen from Fig. 1, there was exponential inactivation of transducing as well as of plaque-forming activity as a function of dose of u.v. radiation. It has been observed previously that exponential u.v. inactivation is associated with transduction of genetic determinants that are not integrated into the recipient chromosome. On the other hand, u.v.-irradiation, in low doses, has been observed to increase the frequency of stable recombinants for markers that apparently are integrated (Fig. 1, broken curve), (Garen \& Zinder, 1955; Arber, 1960; Korman \& Berman, 1962).

Effect of acridine orange. Ultraviolet-irradiation (Bondi et al. 1953) and EMS treatment did not increase the frequency of pen-sd variants, nor did growth in the presence of acridine orange. Table 8 shows the results of experiments in which single colonies of several strains were picked and grown in the presence of acridine orange according to the procedure of Hirota (1960). For testing, the cultures were plated to give well-separated colonies which were assayed by the starch iodide test for penicillinase (Perret, 1954). As shown in Table 8, the frequencies of penicillinase-negative colonies were similar for all of the four strains tested whether growth had taken place with or without acridine orange. 


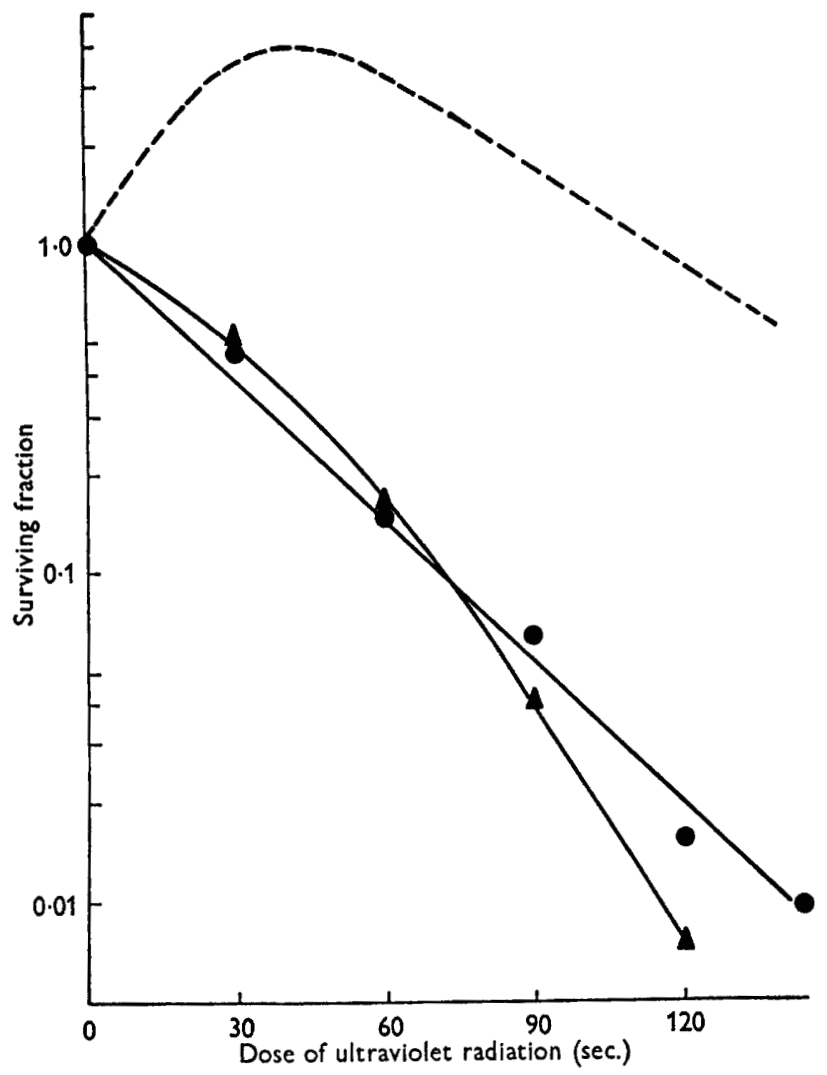

Fig. 1. The effect of ultraviolet-irradiation on a penicillinase-transducing phage lysate. Phage $80 \propto$, propagated on Staphylococcus aureus 8325-18, was diluted in phage buffer to give $10^{10}$ plaque-forming units $/ \mathrm{ml}$. and was $u . v$--irradiated for various lengths of time. Plaque-forming titre $(\Delta)$ and transducing titre for penicillinase ( $\bullet$ ) were determined for each dose of u.v. radiation and are plotted semilogarithmically. The broken curve illustrates the effect of u.v. radiation on transduction of chromosomal markers in Escherichia coli (Garen \& Zinder, 1955; Arber, 1960).

\section{Table 8. Loss of penicillinase in wild-type strains of}

Staphylococcus aureus; effect of acridine orange

\begin{tabular}{|c|c|c|c|c|c|}
\hline \multirow[b]{2}{*}{ Strain } & \multirow[b]{2}{*}{$\begin{array}{l}\text { Growth } \\
\text { cycles* }\end{array}$} & \multicolumn{2}{|c|}{ Control cultures } & \multicolumn{2}{|c|}{ Acridine orange cultures $\dagger$} \\
\hline & & $\begin{array}{c}\text { Total } \\
\text { colonies }\end{array}$ & $\begin{array}{c}\text { Pen-sd } \\
\text { colonies }\end{array}$ & $\begin{array}{l}\text { Total } \\
\text { colonies }\end{array}$ & $\begin{array}{c}\text { Pen-sd } \\
\text { colonies }\end{array}$ \\
\hline $\mathbf{Y}-4$ & $\mathrm{SC} \neq$ & 3030 & 3 & - & - \\
\hline $\mathbf{Y}-4$ & 2 & 4320 & 8 & 4300 & 3 \\
\hline U-9 & SC & 3229 & 6 & - & - \\
\hline U-9 & 2 & 5370 & 16 & 7800 & 15 \\
\hline U-9 & 3 & - & - & 1142 & 5 \\
\hline 524 & 3 & - & - & 2850 & $\mathbf{3}$ \\
\hline $8325-18$ & 3 & $\longrightarrow$ & - & 4355 & 7 \\
\hline
\end{tabular}

* Number of $18 \mathrm{hr}$. subeultures inoculated with $10^{4} \mathrm{organisms} / \mathrm{ml}$.

$\dagger$ Acridine orange concentration used with strain $\mathrm{Y}-4$ was $5 \mu \mathrm{g} . / \mathrm{ml}$.; with all others it was $10 \mu \mathrm{g} . / \mathrm{ml}$.

$\ddagger$ SC signifies single colony picked and plated directly. 


\section{DISCUSSION}

The mutants of Staphylococcus aureus which have been isolated and examined thus far appear to fall into at least three distinct categories : the constitutive group, the inducibles, and the pen-sd strains. The subdivisions within those categories that have been made are arbitrary and were introduced simply for convenience.

\section{Constitutive mutants}

Phenotypically, the constitutive and microconstitutive mutants have alterations in the system which regulates the induction of penicillinase by penicillin. It remains to be seen whether, by analogy with the $\beta$-galactosidase of Escherichia coli (Jacob $\&$ Monod, 1961) or the alkaline phosphatase of the same organism (Garen \& Echols, 1962), there is more than one distinct locus in the regulatory system for penicillinase. It will also be important to work out the dominance relationships between the wild type and its mutant alleles in whatever regulatory loci are found. In any case, if the regulatory locus or loci are distinct from the structural locus, the constitutive mutants should form normal wild-type penicillinase at specific rates which are characteristic of the strains.

\section{Inducible mutants}

The specific genetic alterations responsible for most of the microinducible and mesoinducible mutants have yet to be identified; some information, however, is available. Those genetic alterations thus far examined appear to be point mutants; at least two, both mesoinducible, appear to have structural alterations in the penicillinase molecule; Dr M. H. Richmond (personal communication) has found that the penicillinases produced by these react atypically with anti-penicillinase serum. On the other hand, Dr Richmond has found that others of the inducible group produce penicillinases which react normally with antiserum. The latter might represent mutations involving (1) stability of the enzyme, (2) rate of production and molecular structure, (3) control of enzyme formation, (4) accessibility of enzyme to substrate (cryptic mutants), or (5) antigenic specificity as well as enzymic activity. These possibilities have not yet been examined experimentally, but among them crypticity is considered to be unlikely. This is because many of the mutants have inducibility ratios similar to the wild type as well as lower resistance to penicillin. Crypticity would thus entail the existence of intracellular compartments such that penicillin could penetrate to the site of enzyme induction as well as to the site of its antimicrobial action, while at the same time being unable to reach the sequestered enzyme.

\section{Penicillinase-negative strains}

The attempts at the genetic characterization of the pen-sd and the wild-type penicillinase-negative strains have given rise to the hypothesis of an extrachromosomal mode of inheritance for penicillinase production in Staphylococcus aureus. Under this hypothesis, the extrachromosomal particle involved would simply be missing from the pen-sd and pen-sw strains. Since some of the experiments were undertaken with such a possibility in mind, it is appropriate to review the evidence obtained.

Evidence in favour of extrachromosomal inheritance. (1) The capacity to produce 
penicillinase is frequently lost by individual cocci of most of the strains of Staphylococcus studied here and by other workers (Barber, 1949; Bondi et al. 1953; Fairbrother, 1956). This occurrence is probably too frequent to be accounted for by a chromosomal deletion. Further, its incidence is not increased by mutagens such as ethylmethane sulphonate or ultraviolet radiation. (2) The pen-sd variants of penicillinase-positive strains and the pen-sw strains apparently do not revert to penicillinase production. (3) The pen-sd and pen-sw strains have not been observed to give penicillinase-positive recombinants when crossed to strains with documented point-mutations in the penicillinase region; nor have they been shown to possess the locus which controls inducibility of the enzyme. (4) Ultravioletirradiation of phage produced exponential loss of penicillinase-transducing activity; transduction of other staphylococcal markers was found by Korman \& Berman (1962) to be stimulated by u.v.-irradiation of transducing phage. As pointed out in Results, exponential u.v.-inactivation is characteristic of transduction of genetic particles which do not become integrated into the recipient chromosome. Among the classes of such particles previously studied, all in coliform organisms, are certain of the episomes (Arber, 1960) and chromosomal fragments carried by defective lysogens (Luria et al. 1960). Of these, the latter does not appear to be the situation here because all of $\mathbf{1 0 0}$ transductants tested were found to be sensitive to the transducing phage. If, indeed, an extrachromosomal particle is involved in penicillinase inheritance, in the absence of evidence regarding reversible attachment to the chromosome, the term 'plasmid' (Lederberg, 1952) will be preferable to 'episome' (Jacob \& Wollman, 1958) in describing it. It should be emphasized that the above interpretation of exponential u.v.-inactivation depends on an extrapolation from coliform organisms to staphylococci; the validity of this has still to be tested.

Evidence against extrachromosomal inheritance. No increase in pen-sd mutants resulted from growth in the presence of acridine orange. This compound and other acridine dyes have been found to promote the loss of various plasmids and episomes (Ephrussi, Hottinguer \& Chimenes, 1949; Hirota, 1960; Watanabe \& Fukasawa, 1961), but this has not been found for all such particles (Hirota, 1958). Thus the present results with penicillinase are not necessarily incompatible with extrachromosomal inheritance.

At the present time, there is more evidence in favour of the plasmid hypothesis for penicillinase inheritance in Staphylococcus aureus than against it. However, much of the work reported here is of a preliminary nature and considerably more needs to be done before the question can be settled. Besides further experiments along lines already outlined here, it will be important to determine whether any linkage relationships exist between penicillinase and other markers, and whether the penicillinase region can, like the episomes, be transferred by cell-to-cell contact (Jacob, Schaeffer \& Wollman, 1961).

I am deeply indebted to Dr M. R. Pollock who was a constant source of inspiration. I would like also to acknowledge helpful discussions with Dr D. Dubnau and excellent technical assistance from Mr D. J. McGillicuddy. This work was done during the tenure of a postdoctoral research fellowship from the National Foundation. 


\section{REFERENCES}

Arber, W. (1960). Transduction of chromosomal genes and episomes in Escherichia coli. Virology, 11, 273.

Barber, M. (1949). The incidence of penicillin-sensitive variant colonies in penicillinaseproducing strains of Staphylococcus pyogenes. J. gen. Microbiol. 3, 274.

Barber, M. (1957). Drug resistance of staphylococci with special reference to penicillinase production. In Ciba Foundation Symposium on Drug Resistance in Micro-organisms, p. 262. Ed. G. E. W. Wolstenholme and C. M. O'Connor. London: J. \& A. Churchill, Ltd.

Bondi, A., Kornblum, J. \& de Saint Phalle, M. (1953). Isolation of penicillin-susceptible mutants from penicillinase-producing strains of Micrococcus pyogenes. Proc. Soc. exp. Biol., N.Y. 83, 527.

Csányı, V. (1961). A modified iodometric method of penicillinase assay. Acta physiol. hung. 18, 261.

Ephrussi, B., Hottinguer, H. \& Chimenes, A.-M. (1949). Action de l'acriflavine sur les levures. I. La mutation 'petite colonie'. Ann. Inst. Pasteur, 76, 351.

Fairbrother, R. W. (1956). Mixed staphylococcal infections. The development of penjcillin-resistant strains. Lancet, i, 716.

Fairbrother, R. W., Parker, L. \& Eaton, B. R. (1954). The stability of penicillinaseproducing strains of Staphylococcus aureus. J. gen. Microbiol. 10, 309.

Garen, A. \& Echols, H. (1962). Properties of two regulating genes for alkaline phosphatase. J. Bact. 83, 297.

Garen, A. \& Zinder, N. D. (1955). Radiological evidence for partial genetic homology between bacteriophage and host bacteria. Virology, 1, 347.

Geronimus, L. H. \& Cohen, S. (1957). Induction of staphylococeal penicillinase. $J$. Bact. 73, 28.

Gladstone, G. P. \& Fildes, P. (1940). A simple culture medium for general use without meat extract or peptone. Brit. J. exp. Path. 21, 161.

HrRota, Y. (1958). Inheritance of an environmental effect in the sex-compatibility of Escherichia coli $\mathrm{K} 12$ and its significance. Ph.D. Thesis, Osaka University.

Hinota, Y. (1960). The effect of acridine dyes on mating type factors in Escherichia coli. Proc. nat. Acad. Sci., Wash. 46, 57.

$\mathrm{J}_{\mathrm{ACOB}}, \mathrm{F}$. \& MoNOD, J. (1961). Genetic regulatory mechanisms in the synthesis of proteins. J. molec. Biol. 3, 318.

J ACOB, F. \& Wollman, E. L. (1958). Les episomes, éléments génétiques ajoutés. C.R. Acad. Sci., Paris, 247, 154.

Jacob, F., Schaeffer, P. \& Wollman, E. L. (1961). Episomic elements in bacteria. In Microbial Genetics. Symp. Soc. gen. Microbiol. 10,67.

KNox, R. \& Sмiтh, J. T. (1961). Use of cellulose acetate membranes for detecting penicillinase-producing organisms. Nature, Lond. 191, 926.

Kogut, M., Pollock, M. R. \& Tridgelx, E. J. (1956). Purification of penicillin-induced penicillinase of Bacillus cereus NRRL 569: a comparison of its properties with those of a similarly purified penicillinase produced spontaneously by a constitutive mutant strain. Biochem. J. 62, 391.

Korman, R. Z. \& Berman, O. T. (1962). Transduction with staphylophage. J. Bact. 84, 228.

Lederberg, J. (1952). Cell genetics and hereditary symbiosis. Physiol. Rev. $32,403$.

Loveless, A. \& Howarth, S. (1959). Mutation of bacteria at high levels of survival by ethyl methane sulphonate. Nature, Lond. 184, 1780.

Luria, S. E., Adams, J. N. \& Trng, R. C. (1960). Transduction of lactose-utilizing ability among strains of $E$. coli and $S$. dysenteriae and the properties of the transducing phage particles. Virology, $12,348$.

Novick, R. P. (1962a). Staphylococcal penicillinase and the new penicillins. Biochem. J. 83, 229.

Novick, R. P. (1962b). Micro-iodometric assay for penicillinase. Biochem. J. 83, 236. 
Pattee, P. A. \& Baldwin, J. N. (1961). Transduction of resistance to chlortetracycline and novobiocin in Staphylococcus aureus. J. Bact. 82, 875.

Perret, C. J. (1954). Iodometric assay of penicillinase. Nature, Lond. 174, 1012.

Pollock, M. R. (1957). Penicillin-induced resistance to penicillin in cultures of Bacillus cereus. In Ciba Foundation Symposium on Drug Resistance in Micro-organisms, p. 78. Ed. G. E. W. Wolstenholme and C. M. O'Connor. London: J. \& A. Churchill, Ltd.

Pollock, M. R. \& Torriani, A.-M. (1953). Purification et caractéristiques physiochimiques de la pénicillinase de Bacillus cereus. C.R. Acad. Sci., Paris, 237, 276.

RITZ, H. L. \& BaLDWIN, J. N. (1961). Transduction of capacity to produce staphylococcal penicillinase. Proc. Soc. exp. Biol., N.Y. 107, 678.

RoGERs, H. J. (1953). Variant populations within a hyaluronidase-producing culture of Staphylococcus aureus. J. Path. Bact. 66, 545.

Stamp, Lond (1947). The preservation of bacteria by drying. J. gen. Microbiol. 1, 251.

Strauss, B. (1962). Response of Escherichia coli auxotrophs to heat after treatment with mutagenic alkyl methanesulfonates. J. Bact. 83, 241.

Swanstrom, M. \& Adams, M. H. (1951). Agar layer method for production of high titer phage stocks. Proc. Soc. exp. Biol., N.Y. 78, 372.

Watanabe, T. \& Fukasawa, 'T. (1961). Episome-mediated transfer of drug resistance in Enterobacteraceae. II. Elimination of resistance factors with acridine dyes. J. Bact. 81, 679 . 